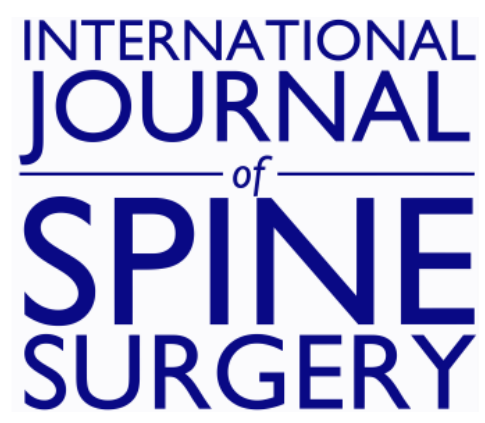

\title{
Correlation of Voice Hoarseness and Vocal Cord Palsy: A Prospective Assessment of Recurrent Laryngeal Nerve Injury Following Anterior Cervical Discectomy and Fusion
}

Anirudh K. Gowd, Nima A. Vahidi, William P. Magdycz, Pamela L. Zollinger and Jonathan J. Carmouche

Int J Spine Surg 2021, 15 (1) 12-17

doi: https://doi.org/10.14444/8001

http://ijssurgery.com/content/15/1/12

This information is current as of April 25, 2023.

Email Alerts Receive free email-alerts when new articles cite this article. Sign up at: http://ijssurgery.com/alerts 


\title{
Correlation of Voice Hoarseness and Vocal Cord Palsy: A Prospective Assessment of Recurrent Laryngeal Nerve Injury Following Anterior Cervical Discectomy and Fusion
}

\author{
ANIRUDH K. GOWD, MD, ${ }^{1}$ NIMA A. VAHIDI, MD, ${ }^{2}$ WILLIAM P. MAGDYCZ, MD,${ }^{3}$ PAMELA L. \\ ZOLLINGER, MD, ${ }^{3}$ JONATHAN J. CARMOUCHE, $\mathrm{MD}^{3}$ \\ ${ }^{1}$ Department of Orthopaedic Surgery, Wake Forest University Baptist Medical Center, Winston-Salem, North Carolina ${ }^{2}$ Department of Orthopaedic Surgery, \\ Virginia Commonwealth University Medical Center, Richmond, Virginia ${ }^{3}$ Department of Orthopedic Surgery, Virginia Tech Carilion School of Medicine, \\ Roanoke, Virginia
}

\begin{abstract}
Background: Injury to the recurrent laryngeal nerve (RLN) has been implicated as a common complication following anterior cervical discectomy and fusion (ACDF) surgery. The purpose of this study is to determine the true incidence of voice hoarseness and RLN palsy following ACDF surgery, to determine the reliability of symptoms in the diagnosis of RLN injury, and to evaluate factors related to the development of these symptoms.

Methods: All patients undergoing elective (primary or secondary) ACDF surgery at a single institution consented to and enrolled in the present study. All approaches were through the left side. Enrolled patients received both preoperative and postoperative (within 1 month following surgery) laryngoscopy by a fellowship-trained ENT physician for evaluation of RLN function. Patients also responded as to whether they were experiencing postoperative symptoms of dysphagia, aspiration, and voice changes.

Results: In total, 108 patients were included in this study. Mean age of the population was $59.2 \pm 10.7$ years and mean body mass index was $31.2 \pm 7.1 \mathrm{~kg} / \mathrm{m}^{2}$. Three patients had previously undergone a thyroidectomy, whereas 20 patients had undergone a previous ACDF. Average intubation time for ACDF surgery was $121.6 \pm 38.5$ minutes. After surgery and excluding patients who were experiencing preoperative symptoms, 19 patients $(20.4 \%)$ complained of dysphagia, 2 patients $(1.9 \%)$ complained of aspiration symptoms, and 5 patients $(4.6 \%)$ complained of voice hoarseness. There was no incidence of vocal cord palsy from postoperative laryngoscopy. From multivariate analysis, endotracheal cuff pressure after retractor placement was correlated to postoperative voice hoarseness, dysphagia, and aspiration symptoms.

Conclusions: From the results of this prospective study, the RLN remained functional even a month after surgery despite several cases of postoperative dysphagia, aspiration, and voice changes. Endotracheal cuff pressure, number of vertebral levels, body mass index, and intubation time were important variables related to postoperative symptoms.

Clinical Relevance: Voice hoarseness does not necessarily indicate recurrent laryngeal nerve injury after ACDF but may be caused by compressive forces on laryngeal tissue during retraction or intubation. Laryngoscopy should be performed in cases with high clinical suspicion.
\end{abstract}

Level of Evidence: 2.

Cervical Spine

Keywords: recurrent laryngeal nerve, complications, anterior cervical discectomy and fusion, voice hoarseness

\section{INTRODUCTION}

Anterior cervical discectomy and fusion (ACDF) is presently the powerhouse operation for the management of progressive cervical spondylosis that may result in either radiculopathy or myelopathy. ${ }^{1,2}$ Recent literature cited a growth in the frequency of this procedure by as high as $400 \%$ prior to $2011 .^{3}$ Growth rates of this procedure is largely attributable to the cost effectiveness of this procedure at a willingness-to-pay threshold of
$\$ 50000$ up to 7 years postoperatively. ${ }^{4-6}$ However, despite the growing popularity of ACDF, there remains a paucity of literature characterizing less severe but more common short-term complications such as dysphonia and dysphagia.

Voice changes following ACDF are common due to proximity of the recurrent laryngeal nerve (RLN) and also depend on approach laterality. ${ }^{7}$ Incidence rates of voice hoarseness and RLN palsy have been reported to range between $1 \%$ and $70 \%$ following 
ACDF. ${ }^{7-12}$ The large variability in this incidence is predominantly a result of inconsistent measurements of vocal cord function. ${ }^{7-12}$ However, bilateral RLN palsy, occurring from subsequent anterior neck surgeries through contralateral approaches, will result in airway obstruction and require tracheostomy. ${ }^{12-14}$

A thorough evaluation of the RLN is important for preoperative risk assessment in avoiding this complication. ${ }^{14}$ A direct laryngoscopy is the diagnostic tool of choice for this evaluation, though the decision to perform this procedure is dependent on patient surgical history, medical history, and preoperative symptomatology. ${ }^{11}$ However, vocal cord symptoms may be related to pathology of alternate structures, such as arytenoids or other laryngeal nerves, or may not necessarily constitute a palsy of the RLN. ${ }^{11}$ To better inform clinicians on the need for direct laryngoscopy prior to ACDF, an evaluation of the relationship between vocal cord symptoms and palsy is required.

The purpose of this study was to determine the true incidence of voice hoarseness and RLN palsy following ACDF surgery, to determine the reliability of symptoms in the diagnosis of RLN injury, and to evaluate factors related to the development of these symptoms. The hypothesis was that voice hoarseness and dysphagia are poor indicators for RLN injury.

\section{METHODS}

Following institutional review board approval, all patients undergoing ACDF surgery were prospectively enrolled from 2016 to 2018 for participation within this study. Inclusion criteria were all individuals undergoing elective $\mathrm{ACDF}$ for either cervical radiculopathy or myelopathy. Patients undergoing revision surgery and secondary neck surgery (ie, prior thyroid surgery) were not excluded, but these variables were collected and used in multivariate analysis. Special populations, including pregnant women, prisoners, and minors, were ineligible for enrollment. In addition, aberrant findings from the preoperative laryngoscopy excluded patients from participation. No compensation was provided for participation, although additional costs for laryngoscopy and data collection were not imposed on the patient.

Consent for participation was obtained during preoperative consultation. Participants were asked to undergo a preoperative laryngoscopy from a single fellowship-trained ENT physician. Direct and indirect laryngoscopy exams were used to evaluate the function of the vocal cords. Asymmetric vocal folds movement was considered an abnormal finding suggestive of vocal cord dysfunction. Intraoperatively, the endotracheal cuff pressure was measured using an external syringelike device approved by the Food and Drug Administration for endotracheal pressure control (ApnoGuard Cuffill Manometer, Hospitech Respiration, Kfar Saba, Israel). Case anesthesiologists were instructed to measure the endotracheal cuff pressure immediately after intubation, immediately before final retractor placement, immediately after final retractor placement, and at 30-minute intervals following placement of retractors. Cuff pressure was not controlled, and anesthesiologists were asked to inflate the cuff per normal cases.

Postoperative laryngoscopy was scheduled within 4 weeks of indexed surgery by the same ENT physician. Patients were also asked whether they were experiencing any difficulty eating (dysphagia), voice hoarseness, and aspiration.

\section{Surgical Technique}

Patients were positioned supine on a flat Jackson operating room table. A 3- to 4-cm transverse incision was made at left side of the anterior neck at the level of the relevant vertebral interspace. A leftsided approach was routinely used given the increased risk of recurrent laryngeal nerve palsy from right-sided approaches. ${ }^{15}$ Dissection was performed through the platysma, and internervous planes were developed between the sternocleidomastoid and strap muscles and the longus colli muscles. Self-retaining retractors were placed within these planes to retract relevant structures, and pins were drilled into the superior and inferior vertebral bodies to keep these retractors in place. An annulotomy was performed and the anterior longitudinal ligament incised. Discectomy was performed using kerosene, rongeurs, and curettes until the posterior longitudinal ligament was reached. Bone allograft or iliac crest autograft was used to fill the vertebral interspace. An appropriately sized anterior cervical plate was placed anterior to the vertebral bodies, and self-tapping screws were used to fix the plate to the superior and inferior vertebral bodies. Steroids were not used intraoperatively to minimize risk of postoperative dysphagia. 
Table 1. Population characteristics of those included for prospective study.

\begin{tabular}{lc}
\hline Parameter & Value \\
\hline Demographic, mean \pm SD & \\
$\quad$ Age, y & $59.2 \pm 10.7$ \\
BMI, kg/m² & $31.2 \pm 7.1$ \\
Relevant medical history (incidence), n (\%) & \\
Hx Thyroidectomy & $3(2.8)$ \\
Hx ACDF & $20(18.5)$ \\
Hx Smoking & $21(19.4)$ \\
Vertebral level (incidence), n (\%) & \\
C2-3 & 0 \\
C3-4 & $20(18.5)$ \\
C4-5 & $56(51.9)$ \\
C5-6 & $90(83.3)$ \\
C6-7 & $64(59.3)$ \\
C7-T1 & $5(4.6)$ \\
T1-2 & $1(0.9)$ \\
\hline
\end{tabular}

\section{Statistical Analysis}

Statistical analysis was performed using RStudio (RStudio, Inc, Boston, MA). Power analysis was performed prior to enrollment. An incidence of symptomatic vocal cord palsy has been reported to be $5 \%$, whereas asymptomatic palsy was reported to be $15 \% .{ }^{11}$ Differentiating these populations would require a sample size of 78 patients. Projected enrollment was 120 patients. The incidences of vocal cord dysfunction and postoperative symptoms were analyzed and correlated. Multivariate logistic regression was used to determine variables associated with increased risk of abnormal vocal cord function and postoperative symptoms.

\section{RESULTS}

After completion of enrollment, 108 patients completed all follow-up laryngoscopies. Twelve patients missed follow-up appointments and were dropped from the study. Mean age of the population was $59.2 \pm 10.7$ years and mean body mass index (BMI) was $31.2 \pm 7.1 \mathrm{~kg} / \mathrm{m}^{2}{ }^{2}$ Three patients had previously received a thyroidectomy, whereas 20 patients received a previous ACDF. The average number of vertebral levels operated were $2.3 \pm 0.9$ (Table 1).

Average intubation time for ACDF surgery was $121.6 \pm 38.5$ minutes. Endotracheal cuff pressure measurements are available in Table 2.

Preoperative laryngoscopy was performed at an average of $13.1 \pm 9.1$ days prior to ACDF. Prior to surgery, 7 patients $(6.5 \%)$ complained of existing dysphagia, 1 patient $(0.9 \%)$ complained of existing aspiration symptoms, and 3 patients $(2.8 \%)$ complained of existing voice hoarseness. Postoperative laryngoscopy was performed at an average of 20.2
Table 2. Intubation characteristics, time, and cuff pressure of included cases during anterior cervical discectomy and fusion.

\begin{tabular}{lc}
\hline Variable & Value (Mean \pm SD) \\
\hline Endotracheal tube size, mm & $7.2 \pm 0.3$ \\
Intubation time, min & $121.6 \pm 38.5$ \\
Endotracheal cuff pressure, mm Hg & $29.9 \pm 14.1$ \\
$\quad$ Postintubation & $32.3 \pm 17.5$ \\
Prior to retractor placement & $45.6 \pm 20.7$ \\
After retractor placement $(0 \mathrm{~min})^{\mathrm{a}}$ & $39.0 \pm 20.7$ \\
After retractor placement $(30 \mathrm{~min})^{\mathrm{a}}$ & $31.8 \pm 16.3$ \\
${\text { After retractor placement }(60 \mathrm{~min})^{\mathrm{a}}}^{\mathrm{a}}$ & $32.1 \pm 13.8$ \\
${\text { After retractor placement }(90 \mathrm{~min})^{\mathrm{a}}}_{\text {After retractor placement }(120 \mathrm{~min})^{\mathrm{a}}}$ & $29.4 \pm 19.0$ \\
\hline
\end{tabular}

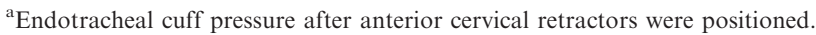

\pm 11.1 days after ACDF. After surgery and excluding patients who were experiencing preoperative symptoms, 19 patients (20.4\%) complained of dysphagia, 2 patients $(1.9 \%)$ complained of aspiration symptoms, and 5 patients $(4.6 \%)$ complained of voice hoarseness. There was no incidence of vocal cord palsy from postoperative laryngoscopy.

Multivariate stepwise logistic regression was performed to determine factors associated with the development of postoperative dysphagia, aspiration symptoms, and voice hoarseness. No associations could be made toward vocal cord palsy, because there was no incidence of this complication (Table $3)$.

Table 3. Multivariate analysis of variables associated with postoperative voice hoarseness, dysphagia, and aspiration symptoms. ${ }^{a}$

\begin{tabular}{|c|c|c|c|}
\hline Variable & $\begin{array}{l}\text { Odds } \\
\text { Ratio }\end{array}$ & $\begin{array}{c}\text { Confidence } \\
\text { Interval }\end{array}$ & $\begin{array}{c}P \\
\text { Value }\end{array}$ \\
\hline \multicolumn{4}{|l|}{ Postoperative voice hoarseness } \\
\hline BMI, $\mathrm{kg} / \mathrm{m}^{2}$ & 0.993 & $0.987-0.998$ & .014 \\
\hline Cuff before retractors ${ }^{b}$ & 0.996 & $0.993-0.999$ & .024 \\
\hline Cuff pressure $(30 \mathrm{~min})^{b}$ & 1.004 & $1.001-1.007$ & .042 \\
\hline Cuff pressure $(90 \mathrm{~min})^{\mathrm{b}}$ & 1.009 & $0.999-1.018$ & .064 \\
\hline Intubation time & 1.001 & $0.999-1.003$ & .059 \\
\hline \multicolumn{4}{|l|}{ Postoperative dysphagia } \\
\hline Age, $y$ & 0.949 & $0.825-1.015$ & .112 \\
\hline BMI, $\mathrm{kg} / \mathrm{m}^{2}$ & 0.915 & $0.825-1.015$ & .094 \\
\hline C3-C4 Level & 37.463 & $6.689-209.823$ & $<.001$ \\
\hline Cuff pressure $(0 \mathrm{~min})^{b}$ & 8.590 & $7.609-9.981$ & .014 \\
\hline Cuff pressure $(30 \mathrm{~min})^{b}$ & 1.201 & $1.065-1.353$ & .003 \\
\hline Cuff pressure $(60 \text { min })^{b}$ & 0.861 & $0.743-0.998$ & .047 \\
\hline Cuff pressure $(90 \mathrm{~min})^{\mathrm{b}}$ & 1.231 & $0.915-1.657$ & .169 \\
\hline Cuff pressure $(120 \mathrm{~min})^{\mathrm{b}}$ & 0.781 & $0.567-1.075$ & .130 \\
\hline ETT size $(\mathrm{mm})$ & 0.126 & $0.005-2.554$ & .170 \\
\hline \multicolumn{4}{|c|}{ Postoperative aspiration symptoms } \\
\hline BMI, $\mathrm{kg} / \mathrm{m}^{2}$ & 0.997 & $0.993-1.000$ & .057 \\
\hline Cuff pressure $(0 \mathrm{~min})^{\mathrm{b}}$ & 0.999 & $0.997-1.000$ & .150 \\
\hline Cuff pressure $(120 \mathrm{~min})^{\mathrm{b}}$ & 0.989 & $0.983-0.995$ & .001 \\
\hline Intubation time (min) & 1.001 & $1.000-1.001$ & .025 \\
\hline
\end{tabular}

Abbreviations: ACDF, anterior cervical discectomy and fusion; BMI, body mass index; ETT, endotracheal tube.

${ }^{\mathrm{a}}$ Bold indicatea statistical significance $(P<.05)$.

${ }^{\mathrm{b}}$ Endotracheal cuff pressure at time intervals following ACDF retractor

placement measured in millimeters of mercury. 

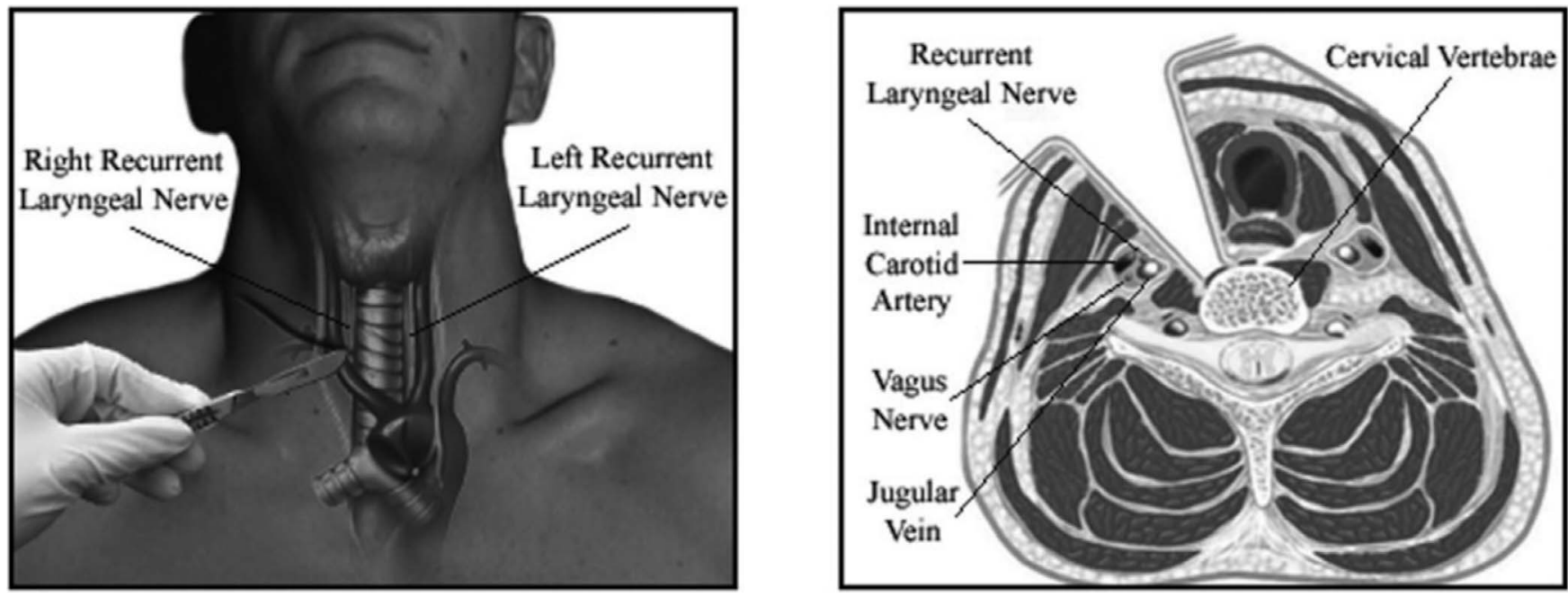

Figure. Injury to the recurrent laryngeal nerve may be a greater risk through use of anterior cervical retractor systems. Reprinted with permission from Gowd et al. ${ }^{14}$

\section{DISCUSSION}

The primary findings of this study would suggest that RLN palsy is rarer than previously thought. Short-term palsy was not found in any of the 108 patients enrolled in the study. However, voice hoarseness and dysphagia were prevalent postoperative complaints following ACDF surgery. In addition, endotracheal cuff pressure, particularly after the placement of ACDF retractors, had a significant influence over these postoperative symptoms. This would suggest that the mechanism of injury to laryngeal structures may be compressive in nature rather than the effect of surgical dissection. Prudent measures of cuff pressure and retractor placement may be alternative strategies in the prevention of dysphonia, dysphagia, and postoperative aspiration.

The high variability in the incidence of RLN palsy following ACDF is largely attributable to diagnostic differences. ${ }^{7-12}$ Whereas direct laryngoscopy is the "gold standard" in evaluating RLN function, there are indirect modes to measure nerve activity because vocal cord motion is truly being evaluated. ${ }^{16}$ Electromyography monitoring by placing electrodes along the posterior pharynx is an alternative method of measuring changes in a nerve. ${ }^{17}$ Intraoperative nerve monitoring was recently shown ${ }^{18}$ to have high diagnostic value when nerve potentials were below $200 \mathrm{mEV}$ in predicting vocal cord palsy with sensitivity, specificity, and negative and positive predictive values greater than $70 \%$. However, considering the low incidence of RLN palsy, the additional costs of using this monitoring may not be cost-effective. ${ }^{7-12}$
At present, the most prominent risk factor for developing RLN injury is neck reoperation for failed fusion. ${ }^{19}$ In evaluation of patients undergoing secondary neck surgery, Erwood et $\mathrm{al}^{11}$ demonstrated that $7.5 \%$ of patients developed RLN palsy through direct laryngoscopy. Although the present study did not find reoperations to be related to dysphonia or dysphagia, study findings did corroborate the literature suggesting that elevated endotracheal cuff pressure, C3-C4 vertebral levels, and intubation time were correlated with postoperative symptoms. ${ }^{20}$ Operation at the $\mathrm{C} 3-\mathrm{C} 4$ vertebral level has close proximity to the glossopharyngeal, hypoglossal, and the upper laryngeal nerves. As demonstrated in a prior study, ${ }^{21}$ increased intraoperative pressure due to endotracheal cuff pressure and retractors likely play a large role in postoperative dysphagia.

The findings of this study would imply that the primary mechanism of injury is through direct compression or traction of the RLN rather than accidental resection. These findings are fairly consistent with the accepted anatomic variability of the RLN (Figure). ${ }^{22}$ The endotracheal tube cuff, when inflated, has been reported to exert direct compression forces that can induce nerve ischemia. ${ }^{19}$ Furthermore, this pressure is only exacerbated by the presence of cervical retractors in the mediastinum, as corroborated by the present study. ${ }^{20,23}$ However, a previously designed study to examine the effect of reduced endotracheal cuff pressure as an intervention, failed to demonstrate any significant improvement in the incidence of RLN palsy. ${ }^{24}$ Alternatively, excess stretch of the 
RLN through excess retraction may also result in substantial damage. ${ }^{20,25}$ Stretch of a nerve beyond $15 \%$ its base length has been shown to produce irreversible damage in animal models. ${ }^{26,27}$ From findings of the present study, it is likely that there is an additive effect of retractor placement and increased endotracheal cuff pressure that results in voice hoarseness. Furthermore, increased BMI may increase intraoperative pressure and subsequently add to postoperative symptoms. These apparent findings may suggest that attention be paid to each of these contributions during surgery in order to minimize postoperative hoarseness.

The primary limitation of this study is within its design. Although the study is prospective, there was little controlling of variables. Therefore, the population in the study is largely heterogeneous. There exist multiple different vertebral levels, endotracheal tube cuff pressures, and primary and secondary surgeries that were included. In addition, sample size was a primary limitation because this study was underpowered. Continued research should be done with higher-level evidence and testing for 1 of these known risk factors while controlling for others.

\section{CONCLUSION}

From the results of this prospective study, the RLN remained functional even within a month from surgery despite several cases of postoperative dysphagia, aspiration, and voice changes. Endotracheal cuff pressure, number of vertebral levels, BMI, and intubation time were important variables related to postoperative symptoms.

\section{REFERENCES}

1. Qureshi SA, McAnany S, Goz V, Koehler SM, Hecht AC. Cost-effectiveness analysis: comparing single-level cervical disc replacement and single-level anterior cervical discectomy and fusion: clinical article. J Neurosurg Spine. 2013;19(5):546-554. doi:10.3171/2013.8.SPINE12623

2. Alvin MD, Qureshi S, Klineberg E, et al. Cervical degenerative disease: systematic review of economic analyses. Spine (Phila Pa 1976). 2014;39(22 suppl 1):S53-S64. doi:10. 1097/BRS.0000000000000547

3. Arrojas A, Jackson JB 3rd, Grabowski G. Trends in the treatment of single and multilevel cervical stenosis: a review of the American Board of Orthopaedic Surgery database. J Bone Joint Surg Am. 2017;99(18):e99. doi:10.2106/JBJS.16.01082

4. Poorman GW, Passias PG, Qureshi R, et al. Cost-utility analysis of cervical deformity surgeries using 1-year outcome. Spine J. 2018;18(9):1552-1557. doi:10.1016/j.spinee.2018.01.016

5. Merrill RK, McAnany SJ, Albert TJ, Qureshi SA. Is twolevel cervical disc replacement more cost-effective than anterior cervical discectomy and fusion at 7 years? Spine (Phila Pa 1976). 2018;43(9):610-616. doi:10.1097/BRS. 0000000000002380

6. McAnany SJ, Merrill RK, Overley SC, Kim JS, Brochin RL, Qureshi SA. Investigating the 7-year cost-effectiveness of single-level cervical disc replacement compared to anterior cervical discectomy and fusion. Global Spine J. 2018;8(1):32-39. doi: $10.1177 / 2192568217726283$

7. Beutler WJ, Sweeney CA, Connolly PJ. Recurrent laryngeal nerve injury with anterior cervical spine surgery risk with laterality of surgical approach. Spine (Phila Pa 1976). 2001;26(12):1337-1342. doi:10.1097/00007632-20010615000014

8. Frempong-Boadu A, Houten JK, Osborn B, et al. Swallowing and speech dysfunction in patients undergoing anterior cervical discectomy and fusion: a prospective, objective preoperative and postoperative assessment. J Spinal Disord Tech. 2002;15(5):362-368.

9. Chang SW, Kakarla UK, Maughan PH, et al. Four-level anterior cervical discectomy and fusion with plate fixation: radiographic and clinical results. Neurosurgery. 2010;66(4):637639. doi:10.1227/01.NEU.0000367449.60796.94

10. Smith-Hammond CA, New KC, Pietrobon R, Curtis DJ, Scharver $\mathrm{CH}$, Turner DA. Prospective analysis of incidence and risk factors of dysphagia in spine surgery patients: comparison of anterior cervical, posterior cervical, and lumbar procedures. Spine (Phila Pa 1976). 2004;29(13):1441-1446.

11. Erwood MS, Walters BC, Connolly TM, et al. Voice and swallowing outcomes following reoperative anterior cervical discectomy and fusion with a 2-team surgical approach. $J$ Neurosurg Spine. 2018;28(2):140-148. doi:10.3171/2017.5. SPINE161104

12. Paniello RC, Martin-Bredahl KJ, Henkener LJ, Riew KD. Preoperative laryngeal nerve screening for revision anterior cervical spine procedures. Ann Otol Rhinol Laryngol. 2008;117(8):594-597.

13. Nikandish R, Zareizadeh A, Motazedian S, Zeraatian S, Zakeri H, Ghaffarpasand F. Bilateral vocal cord paralysis after anterior cervical discectomy following cervical spine injury: a case report. Bull Emerg Trauma. 2013;1(1):43-45.

14. Gowd A, Nazemi A, Carmouche J, Albert T, Behrend C. Indications for direct laryngoscopic examination of vocal cord function prior to anterior cervical surgery. Geriatr Orthop Surg Rehabil. 2017;8(1):54-63. doi:10.1177/2151458516681144

15. Morpeth JF, Williams MF. Vocal fold paralysis after anterior cervical diskectomy and fusion. Laryngoscope. 2000;110(1):43-46. doi:10.1097/00005537-200001000-00009

16. Mohil RS, Desai P, Narayan N, Sahoo M, Bhatnagar D, Venkatachalam VP. Recurrent laryngeal nerve and voice preservation: routine identification and appropriate assessment-two important steps in thyroid surgery. Ann $R$ Coll Surg Engl. 2011;93(1):49-53. doi:10.1308/ 003588410X12771863936927

17. Jellish WS, Jensen RL, Anderson DE, Shea JF. Intraoperative electromyographic assessment of recurrent laryngeal nerve stress and pharyngeal injury during anterior cervical spine surgery with Caspar instrumentation. J Neurosurg. 1999;91(suppl 2):170-174.

18. Genther DJ, Kandil EH, Noureldine SI, Tufano RP. Correlation of final evoked potential amplitudes on intraoperative electromyography of the recurrent laryngeal nerve with immediate postoperative vocal fold function after thyroid and 
parathyroid surgery. JAMA Otolaryngol Head Neck Surg. 2014;140(2):124-128. doi:10.1001/jamaoto.2013.6139

19. Apfelbaum RI, Kriskovich MD, Haller JR. On the incidence, cause, and prevention of recurrent laryngeal nerve palsies during anterior cervical spine surgery. Spine (Phila $\mathrm{Pa}$ 1976). 2000;25(22):2906-2912. doi:10.1097/00007632200011150-00012

20. Sperry RJ, Johnson JO, Apfelbaum RI. Endotracheal tube cuff pressure increases significantly during anterior cervical fusion with the Caspar instrumentation system. Anesth Analg. 1993;76(6):1318-1321. http://www.ncbi.nlm.nih.gov/pubmed/ 8498671

21. Wu B, Song F, Zhu S. Reasons of dysphagia after operation of anterior cervical decompression and fusion. Clin Spine Surg. 2017;30(5):E554-E559. doi:10.1097/BSD. 0000000000000180

22. Ling XY, Smoll NR. A systematic review of variations of the recurrent laryngeal nerve. Clin Anat. 2016;29(1):104-110. doi:10.1002/ca.22613

23. Garg R, Rath GP, Bithal PK, Prabhakar H, Marda MK. Effects of retractor application on cuff pressure and vocal cord function in patients undergoing anterior cervical discectomy and fusion. Indian J Anaesth. 2010;54(4):292-295. doi:10.4103/ 0019-5049.68370

24. Jung A, Schramm J. How to reduce recurrent laryngeal nerve palsy in anterior cervical spine surgery: a prospective observational study. Neurosurgery. 2010;67(1):10-15. doi:10. 1227/01.NEU.0000370203.26164.24

25. Pattavilakom A, Seex KA. Comparison of retraction pressure between novel and conventional retractor systems - a cadaver study. J Neurosurg Spine. 2010;12(5):552-559. doi:10. 3171/2009.11.SPINE0956

26. Brown R, Pedowitz R, Rydevik B, et al. Effects of acute graded strain on efferent conduction properties in the rabbit tibial nerve. Clin Orthop Relat Res. 1993;(296):288-294.

27. Wall EJ, Massie JB, Kwan MK, Rydevik BL, Myers RR, Garfin SR. Experimental stretch neuropathy. Changes in nerve conduction under tension. J Bone Joint Surg Br. 1992;74(1):126-129.

Disclosures and COI: The authors received no funding for the study and report no conflicts of interest. William P. Magdycz has received payments from Intuitive Surgical Inc (food and beverage) that is outside the scope of this article. Jonathan $\mathbf{J}$. Carmouche has received payments from Medtronic Inc (travel and lodging) that is outside the topic of this article. He is also a board or committee member for the American Academy of Orthopedic Surgeons and Scoliosis Research Society.

Corresponding Author: Anirudh K. Gowd, MD, Department of Orthopaedic Surgery, Wake Forest University Baptist Medical Center, 1 Medical Center Blvd, Winston-Salem, NC. Phone: (336) 716-6011; Email: anirudhkgowd@gmail.com.

Published 26 February 2021

This manuscript is generously published free of charge by ISASS, the International Society for the Advancement of Spine Surgery. Copyright (C) 2021 ISASS. To see more or order reprints or permissions, see http://ijssurgery.com. 